mineralogy laboratory, cooling cubes of ice down to the temperature of solid carbon dioxide. At this temperature of $-78 \cdot 5^{\circ} \mathrm{C}$. the hardness of ice was found to be approximately 6 , or that of orthoclase felspar.

Apart from its significance to students of mineralogy, physics and geomorphology, the fact that ice increases in hardness inversely with temperature is of considerable interest to polar travellers. Air temperatures in polar regions often fall below $-50^{\circ} \mathrm{C}$., and temperatures of $-70^{\circ} \mathrm{C}$. are by no means unknown in the coldest parts of the globe. Ice with a hardness of 5 or even 6 should therefore not be uncommon.

These investigations now provide an explanation of the all too familiar stinging sensation of ice crystals striking against the face during blizzards, of the remarkable shapes into which hard snowdrifts are carved at such times, and of the excessive wear on sledge runners at very low temperatures.

\title{
GEOGRAPHIC INCIDENCE OF AURORA AND MAGNETIC DISTURBANCE IN THE NORTHERN AND SOUTHERN HEMISPHERES
}

[Review of papers by E. H. Vestine in Terrestrial Magnetism and Atmospheric Electricity, Vol. 49, No. 2, June 1944, pp. 77-102, and by E. H. Vestine and E. J. Snyder, loc. cit., Vol. 50, No. 2, June 1945, pp. 105-24.]

In the first of these papers the author has extended the well-known memoir published by Fritz in 1881, in which the frequency and characteristics of aurora observed in the Northern Hemisphere during the years 1700-1872 were discussed. Mr Vestine has now constructed a map of isochasms of equal auroral frequency, by using material collected by the International Polar Year expeditions of 1882-83 and 1932-33 and by other expeditions. On his map Fritz did not attempt to draw isochasms inside the zone of maximum auroral frequency; but using statistical methods and making allowances for the influence of cloudiness and daylight, Vestine has attempted to draw isochasms in the region of the geomagnetic pole. The isochasms of auroral frequency are compared with curves of equal geomagnetic disturbance compiled from information obtained during the 1932-33 Polar Year. The curves are similar to the auroral isochasms and the zone of maximum geomagnetic disturbance coincides with the auroral maximum zone.

Owing to comparative scarcity of observations the same methods cannot be used for deriving similar charts for the Southern Hemisphere, and in the second paper the authors have compared the average features of geomagnetic disturbance and aurora in southern latitudes with those derived from more extensive data for northern latitudes. The seasonal and yearly average of the disturbance daily variation is obtained for various stations in Antarctic regions, and its variation in amplitude with latitude is compared with that for the Northern Hemisphere. These data are used to estimate the position of the southern zone of maximum auroral frequency. 
It is perhaps worth pointing out that the information used in constructing the maps in these papers was obtained on various expeditions in different places in different years, and it is an example of how accurate observations made on one expedition can be co-ordinated with other observations and used to build up a valuable whole. Those making observations should always record the absence of aurora and notes on the amount of cloud.

R. A. HAMILTON

\section{EARLY CANNED FOODS FROM THE NORTH-WEST PASSAGE}

By the courtesy of the High Commissioner for Canada we have recently received a copy of a Report on samples of canned foods dating back to the time of the Franklin Search Expeditions. The samples were found by patrols of the Royal Canadian Mounted Police in caches at Beechey Island in Barrow Strait and at Dealy Island off Melville Island. Franklin's ships the Erebus and Terror spent their first winter at Beechey Island in 1845-46, and there is therefore the possibility of some of the cans having been left by Franklin's party. The other locality, Dealy Island, served as a winter base for Kellett and McClintock in the Resolute and Intrepid as the Western Division of Belcher's Squadron in 1852-54, and any cans found there must almost certainly have come from the Resolute and Intrepid. It is not made clear in the Report where the different cans came from.

Examination by the Chemistry Division of the Department of Agriculture, Ottawa, has been made of four cans of Ox-cheek Soup, painted blue and stamped with the name of Gamble, Cork; one can of mutton painted red and without name; one can of carrots painted blue and with the name Gamble stamped on it; and two of sliced carrots, also Gamble products.

In the case of the $\mathrm{Ox}$-cheek Soup two only of the cans were in good condition; the third had a pin-prick hole and the other had leaked. The contents of the two sound cans were more of the nature of a stew than a soup, and appeared to be in excellent condition. The fat indicated no deterioration. Tests for rancidity were negative. The contents of one of the cans were examined for vitamin $B_{1}$ and $B_{2}$. Tests for $B_{1}$ (thiamin) were negative. $B_{2}$ (riboflavin) content was 3 microgrammes per gramme. Five gramme samples fed daily to rats for 14 days gave approximately the same gains in weight as milk.

The mutton can had rusted and was perforated, but the meat appeared to be in good condition, and the fat appeared unchanged. Five grammes fed daily to rats for 14 days gave normal gain in weight.

The carrot tin did not appear to have leaks, but the contents were unrecognisable as carrots either by appearance or flavour. The carrots were badly discoloured and quite inedible. The remaining two tins-of sliced carrot-were in bad condition; the contents were badly discoloured and quite inedible, and no analyses were made. 